\title{
Intoxicación alimentaria por consumo de carne de caimán negro (Melanosuchus niger) en el internado indígena de Nazareth, Amazonas, abril de 1997
}

\author{
Martha C. Suárez ${ }^{1}$, Ligia Pérez ${ }^{2}$, Luz M. Murcia ${ }^{1}$, Luz M. Sarmiento ${ }^{1}$, Silvio Casilimas ${ }^{1}$ \\ 1 Secretaría de Salud del Amazonas, Leticia, Amazonas, Colombia \\ ${ }^{2}$ Servicio de Epidemiologia Aplicada, Instituto Nacional de Salud, Santa Fe de Bogotá, D.C., Colombia
}

\section{Resumen}

Las intoxicaciones alimentarias son ocasionadas por consumo de alimentos en malas condiciones de preparación o de conservación o que han sufrido contaminación con agentes químicos, físicos o biológicos. La reciente incorporación de la vigilancia de este evento en el sistema de vigilancia intensificado de la Secretaría de Salud del Amazonas, ha permitido identificar la presencia de brotes de intoxicación alimentaria en el departamento.

En abril de 1997, se informó a la Oficina de Epidemiología de la Secretaría de Salud del Amazonas, la llegada de 30 pacientes al Hospital Empresa Social del Estado San Rafael de Leticia, con un cuadro clínico de dolor abdominal, vómito y cefalea.

Las pacientes eran estudiantes adolescentes del internado indígena femenino de Nazareth, que presentaban como antecedente común la ingestión de pescado recalentado el día anterior a su consulta.

En la investigación del presente brote de intoxicación alimentaria se comprobó por laboratorio que el alimento implicado era la carne de caimán negro, Melanosuchus niger, contaminada con Bacillus cereus. Esta carne iba a ser vendida como 'pescado seco' en Bogotá, por la gran demanda que tiene este alimento en la época de Semana Santa.

Palabras clave: intoxicación alimentaria, caimán

Food poisoning due to consumption of black cayman meat (Melanosuchus niger) in the Nazareth indigenous school, Amazonas, April 1997

\begin{abstract}
Food poisoning is caused by consumption of food in bad conditions, unproperly stocked or contaminated with chemical or biological agents. The recent incorporation to surveillance of this kind of events in the Amazonas Department Health Office has allowed the identification of such outbreaks in the region.

In April 1997, 30 patients were reported to the Epidemiology Office at the Amazonas Health Office, who had been treated at the San Rafael Hospital of Leticia, for abdominal pain, vomiting and cephalalgya. The patients were adolescent indigenous students of the female school of Nazareth who shared a common exposure, consumption of reheated fish the previous day. The present outbreak study showed that black cayman (Melanosuchus niger) meat was involved in the food poisoning outbreak, and Bacillus cereus was isolated from the sampled specimens. The meat was to be sold as 'dry fish' in Santa Fe de Bogotá, as this kind of fish has a great demand during the Holy Week season.
\end{abstract}

Key words: outbreak, food poisoning, cayman 
Las enfermedades transmitidas por alimentos (ETA) o intoxicaciones alimentarias, son producidas por la ingestión de agua y alimentos contaminados, mal preparados o deficientemente conservados, con cantidades suficientes de agentes químicos y microbiológicos (o sus toxinas) patógenos para el hombre(1).

En Colombia, estos eventos son objeto de vigilancia en salud pública; es responsabilidad del Ministerio de Salud y del Instituto Nacional para la Vigilancia de Medicamentos y Alimentos (INVIMA) expedir las disposiciones legales sobre higiene de alimentos, tales como las definiciones y normas enmarcadas en el Código Sanitario Nacional o Ley 9 de 1979 (2). La reciente incorporación de la vigilancia de este evento en el sistema de vigilancia intensificado, Sistema Alerta Acción, de la Secretaria de Salud del departamento del Amazonas, ha permitido identificar la presencia de brotes.

El 7 de abril de 1997 a las 16:30, se informó a la Oficina de Epidemiología de la Secretaría Departamental de Salud del Amazonas, la llegada de 30 pacientes al Hospital Regional de Leticia, con un cuadro clínico de dolor abdominal, vómito y cefalea. Las pacientes eran estudiantes adolescentes del internado indígena femenino de Nazareth que presentaban como antecedente común, la ingestión de pescado recalentado a las 08:45 del mismo día.

Las pacientes hospitalizadas recibieron atención médica de urgencias y permanecieron en observación. El manejo de los casos en el hospital se realizó con líquidos endovenosos, antiespasmódicos y analgésicos; además, se tomaron muestras de materia fecal para estudio. Se recomendó la toma de muestras de material emético, pero no se llevó a cabo. El equipo de epidemiología de la Secretaría de Salud se desplazó al Hospital Regional para realizar la investigación de las pacientes internas.

Por estar prohibida su comercialización, la carne de caimán negro había sido decomisada por

Correspondencia: Secretaría de Salud, Amazonas

Recibido: 14/10/99; aceptado: 11/02/00
Corpoamazonia (3) que, a su vez, la donó a algunas instituciones donde se concentran grandes grupos poblacionales como la cárcel, el ancianato, la base militar y los internados indigenas, entre ellos el de Nazareth.

El consumo de carne de caimán negro no hace parte de la dieta habitual en algunos grupos étnicos, pues se le considera un animal sagrado del cual descienden; este hecho se pudo convertir en un factor protector, ya que algunas de las estudiantes relataron que por el olor habían identificado el alimento como carne de caimán negro y no pescado seco y optaron por regalarlo a otras compañeras.

Nazareth es una pequeña comunidad indígena Ticuna ubicada a 30 kilómetros de Leticia; cuenta con un internado indígena que pertenece al sistema de educación contratada y que cubre los grados sexto a undécimo, con un total de 150 personas. La presente investigación de campo se llevó a cabo con el propósito de identificar todos los casos de intoxicación alimentaria, identificar el agente causal, caracterizar el brote en tiempo, lugar y persona, aplicar las medidas de intervención requeridas para el control de la situación y establecer medidas para controlar y prevenir la ocurrencia de eventos similares.

\section{Materiales y métodos}

Un equipo de la Secretaría de Salud y del Hospital se desplazó en deslizador al internado indígena Nazareth, ubicado a 40 minutos de Leticia; al internado indígena, que pertenece a la modalidad de educación contratada, asisten niñas que proceden de varias comunidades étnicas del departamento.

El equipo investigador se dividió en dos grupos: el primer grupo solicitó al personal directivo las listas actualizadas de todo el personal del internado indígena, especificando si eran estudiantes, profesores o personal administrativo; a los docentes, se les solicitaron los datos del censo estudiantil de ingreso y de asistencia escolar por grados y por etnias; se indagó sobre los casos precedentes y su manejo a nivel escolar; con el promotor de salud, se recogió información sobre la ocurrencia de casos con síntomas similares en 
la comunidad cercana de Nazareth, distante 20 minutos a pie del internado indígena.

Se elaboró una encuesta para recolectar información concerniente a los alimentos consumidos en las 24 horas previas a la aplicación de la encuesta. Se aplicó la misma encuesta a las estudiantes hospitalizadas en Leticia.

Se difinió como caso a toda persona procedente del internado indígena Nazareth, estudiantes o personal administrativo, que presentara al menos uno de los siguientes síntomas: dolor abdominal, cefalea, fiebre, diarrea, vómito, escalofríos, calambres, deshidratación y náuseas.

Los casos se caracterizaron por lugar, tiempo y persona y se consideraron las siguientes variables de estudio: edad y etnia; fecha y hora de inicio de los síntomas (dolor abdominal, cefalea, fiebre, diarrea, vómito, escalofríos, calambres y deshidratación); día y hora probable de contaminación; hora y tipo de alimentos consumidos; y manejo ambulatorio y hospitalario (4).

El segundo grupo se dedicó a la investigación de la posible fuente de contaminación y realizó una inspección visual de las instalaciones locativas del área del comedor y la cocina, las fuentes de agua, el sistema de eliminación y disposición final de desechos, la manipulación y conservación de los alimentos.

Teniendo en cuenta que las normas organolépticas, físicas, químicas y microbiológicas de la calidad del agua potable rigen en todo el territorio nacional y deben cumplirse en un sistema de suministro de agua potable (5), se tomaron muestras de agua para análisis físico-químico y microbiológico de la quebrada Nazareth que abastece los tanques y de un tanque de agua lluvia que se usa para preparar los alimentos. No fue posible tomar muestras del menú del desayuno del día del brote porque no quedaban restos de los alimentos preparados ese día. Para el análisis microbiológico, se tomaron muestras de tres lotes de carne: uno del costal de donde se sacó la porción que se preparó el día anterior y de dos costales más que estaban almacenados en la despensa. Las muestras se sembraron en medio líquido de agua peptonada y se sembraron en medios específicos y diferenciales tanto para Gram positivos como para Gram negativos. En menos de 24 horas, las muestras recolectadas fueron enviadas al Invima.

Las muestras de agua para el análisis físicoquímico, se transportaron en recipientes de polietileno con capacidad para $500 \mathrm{ml}$; se utilizaron técnicas cuantitativas de tipo volumétrico (Aqua Merck). Para el estudio microbiológico, el agua se recolectó en recipientes estériles de vidrio con capacidad de $500 \mathrm{ml}$. Se realizaron siembras de 1,10 y $100 \mathrm{ml}$ en medios de cultivo específicos para coliformes fecales (Agar MacConkey), coliformes total (Agar Endo) y aerobios mesofílicos (Plate count); estas muestras se procesaron en el laboratorio de la Secretaría de Salud.

Se inspeccionó el sistema de toma, el abastecimiento y el almacenamiento de agua y se indagó sobre la existencia de un programa interno para el control de calidad; posteriormente, se inspeccionaron los sitios de disposición final de los desechos líquidos: aguas servidas provenientes de lavaderos, cocina, lavavajillas y lavamanos, al igual que el emisario final, el sistema de recolección y de disposición final de los desechos sólidos en dormitorios, salones y patios. En las instalaciones locativas, se relacionaron y describieron las áreas de cocina, despensa, cuarto para equipos y utensilios de cocina, área de comedor de docentes y estudiantes. Se hizo inspección de las medidas de higiene y control de alimentos perecederos y no perecederos y de su manipulación.

Se calcularon las tasas de ataque para cada uno de los grados escolares. Luego, se establecieron las tasas de ataque para cada uno de los alimentos consumidos y, por último, se calcularon las razones de riesgo con intervalos de confianza de $95 \%$ (4). El análisis univariado y bivariado se realizó utilizando el paquete estadístico Epi-Info, version $6.03 \mathrm{~b}(6)$.

\section{Resultados}

Con los listados obtenidos, se verificó la existencia de 150 personas (140 estudiantes y 10 entre profesores y personal administrativo), con excepción de dos profesores, entre ellos, la directora. Según el censo estudiantil de ingreso y asistencia escolar por la modalidad de internado, 
todas estaban asistiendo a clases; el rango de edad estaba entre 11 y 20 años. Las estudiantes están distribuidas por grados en proporción similar, con un promedio de 23 estudiantes por grado. Las estudiantes procedían de los municipios de Leticia y Puerto Nariño y de los 8 corregimientos del departamento, y pertenecen a 15 etnias, con predominio de las etnias Ticuna $(51,7 \%)$, Yucuna $(13,7 \%)$ y Huitoto $(12,2 \%)$.

El manejo a nivel escolar estuvo a cargo de la profesora encargada de la enfermería y consistió en el suministro de sales de rehidratación oral, agua de limón y acetaminofén. El promotor de salud manifestó no haber tenido casos similiares en la comunidad. Se aplicó la encuesta a 148 personas (140 estudiantes y 8 profesores) y se identificaron 88 casos, con una tasa de ataque global de $59,5 \%$. Las tasas de ataque más altas se encontraron en los grados sexto y séptimo, respectivamente (cuadro 1). Treinta y dos casos $(36,3 \%)$ requirieron hospitalización. No hubo muertes. Los síntomas más frecuentes fueron: dolor abdominal, 68 casos; cefalea, 48 casos, y vómito, 41 casos (figura 1).

El manejo intrahospitalario consistió en la administración de líquidos endovenosos, antiespasmódicos y analgésicos.

De las 148 personas encuestadas, $115(77,7 \%)$ expresaron haber consumido carne de caimán; $132(89,2 \%)$, arroz; $127(85,8 \%)$, chocolate, y 126 $(85,1 \%)$, pan. El análisis de los datos, en este caso las tasas de ataque por alimento y la diferencia de tasas, mostró que la fuente de contaminación fue la carne de caimán negro. El riesgo de enfermar entre los que consumieron carne de caimán negro fue casi 8 veces mayor que el de los que no la consumieron $\mathrm{RR}=7,8$; IC $95 \%[2,67-23,3]$, con un valor de $p<0,05$. Al comparar la diferencia de las tasas de ataque para cada alimento entre las personas que comieron y que no comieron, se encontró que la carne de caimán tuvo la mayor diferencia de tasas, $64,7 \%$ (cuadro 2).

El período de incubación más corto fue de 15 minutos y el más largo de 11 horas (figura 2). EI período promedio de incubación fue de 4,2 +/-2,3 horas. El $25,9 \%$ de los afectados presentaron los
Cuadro 1. Tasa de ataque en la población del internado indigena Nazareth.

\begin{tabular}{lrcc}
\hline Grado & $\mathrm{n}$ & Sintomáticas & $\begin{array}{c}\text { Tasa de } \\
\text { ataque } \\
(\%)\end{array}$ \\
\hline Sexto & 33 & 24 & 72,7 \\
Séptimo & 35 & 26 & 74,2 \\
Octavo & 14 & 9 & 64,2 \\
Noveno & 16 & 8 & 50,0 \\
Décimo & 24 & 10 & 41,6 \\
Undécimo & 18 & 11 & 61,0 \\
Planta de personal & 8 & 0 & 0,0 \\
Total & 148 & 88 & 59,5 \\
\hline
\end{tabular}

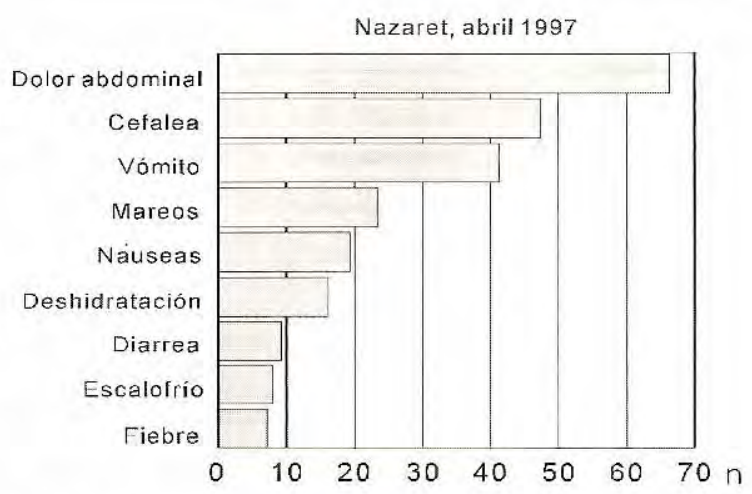

Figura 1. Signos y sintomas presentados por las personas que consumieron caimán negro.

primeros síntomas en la primera hora después de la ingestión del alimento contaminado. Las características de la configuración y duración de la curva epidémica (ascenso rápido del número de casos y un descenso más gradual), sugieren que el brote fue por fuente común.

Se realizaron de tres exámenes coprológicos, los cuales mostraron flora bacteriana normal; los cultivos fueron negativos para otras bacterias enteropatógenas.

Las indagaciones permitieron establecer que en el internado, la carne había estado guardada durante 19 días en bultos en la despensa de la cocina. El lugar era oscuro y húmedo y al realizar la inspección se encontró material en mal estado con manchas rojizas. Esta carne fue preparada para el almuerzo del 6 de abril y los sobrantes guardados en el congelador del internado, el cual queda desconectado durante el día y se conecta sólo en horas de la noche. El 7 de abril, la carne 
Cuadro 2. Tasa de ataque en expuestos y no expuestos a varios alimentos.

\begin{tabular}{|c|c|c|c|c|c|c|c|c|c|c|c|}
\hline \multirow[b]{3}{*}{ Alimento } & \multicolumn{4}{|c|}{ Consumieron alimento } & \multicolumn{4}{|c|}{ No consumieron alimento } & \multirow{3}{*}{$\begin{array}{c}\text { Diferencia } \\
\text { de tasas }\end{array}$} & \multirow{3}{*}{$\begin{array}{c}\text { Razón de } \\
\text { riesgos }\end{array}$} & \multirow[t]{3}{*}{ IC95\% } \\
\hline & \multicolumn{2}{|c|}{ Enfermo } & \multirow[t]{2}{*}{ Total } & \multirow{2}{*}{$\begin{array}{c}\text { Tasa de } \\
\text { ataque } \%\end{array}$} & \multicolumn{2}{|c|}{ Enfermo } & \multirow[t]{2}{*}{ Total } & \multirow{2}{*}{$\begin{array}{c}\text { Tasa de } \\
\text { ataque } \%\end{array}$} & & & \\
\hline & Sí & No & & & Si & No & & & & & \\
\hline Carne de caimán & 85 & 30 & 115 & 73,9 & 3 & 29 & 32 & 9,3 & 64,6 & 7,8 & $2,67-23,3$ \\
\hline Arroz & 85 & 47 & 132 & 64,3 & 3 & 12 & 15 & 20,0 & 44,3 & 3,22 & $1,16-8,93$ \\
\hline Pan & 81 & 45 & 126 & 64,2 & 7 & 14 & 21 & 33,3 & 30,9 & 1,93 & $1,04-3,58$ \\
\hline Chocolate & 80 & 47 & 127 & 63,0 & 7 & 8 & 15 & 46,6 & 7,8 & 1,35 & $0,77-2,36$ \\
\hline
\end{tabular}

se sacó del congelador y fue calentada para su consumo al desayuno. En el momento de consumirla, ya estaba fría. Se obtuvo información de Corpoamazonia sobre las instituciones a las cuales se les había donado la carne y se indagó sobre su consumo, con lo que se comprobó que ya no había existencias en ninguna de las entidades.

En una de las muestras examinadas de carne de caimán negro, perteneciente al lote sobrante del cual se obtuvo la carne con la cual se preparó el desayuno y que se envío al Invima, se aisló Bacillus cereus.

Se comprobó que la carne se almacenó y preparó inadecuadamente, lo que ocasionó su contaminación con la consecuente intoxicación. La carne sobrante se desechó y se dieron las instrucciones correspondientes al personal responsable de la conservación y manipulación de los alimentos.

El abastecimiento de agua proviene de un caño que pasa por el costado norte, donde es captada por medio de una motobomba. El agua llega a dos tanques elevados, construidos en concreto con capacidad para $37,99 \mathrm{~m}^{3}$ y $9,25 \mathrm{~m}^{3}$, respectivamente; de allí, se distribuye a las diferentes áreas del colegio. En el momento de la visita, se encontraban en buen estado de mantenimiento y aseo. Se recoge y utiliza agua lluvia que se almacena en cuatro tanques con capacidad para 1.000 litros cada uno. Estos tanques adolecían de mantenimiento y aseo adecuados. El suministro de agua no es permanente; un pozo perforado está fuera de servicio; no se está clorando el agua, a pesar de

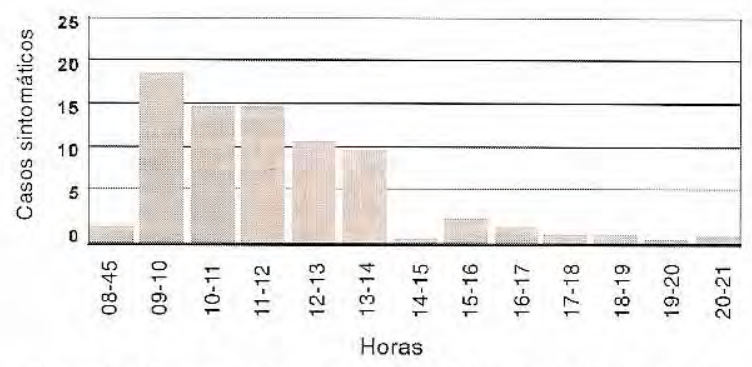

Figura 2. Curva epidémica de la intoxicación alimentaria.

haberse identificado como medida prioritaria en la visita sanitaria No. 212 del 7 de junio de 1996 (7).

En las muestras tomadas de la quebrada y del agua lluvia, no hay presencia de cloro residual libre en ninguno de los puntos de la red de distribución; se observó turbidez con valor alto de 7,6 UNT en agua de la quebrada (valor admisible $\leq 5$ UNT), alteraciones en el color con 30 y 15 UPC, respectivamente (valor admisible $\leq 15$ ); la alcalinidad, el valor potencial de hidrógeno y de cloruros están entre los límites admisibles. Con relación a la calidad bacteriológica, en las muestras tomadas se obtuvo un recuento total de mesófilos y coliformes por encima de los valores permisibles, lo cual la califica como agua no aceptable para el consumo humano (5).

Para la disposición final de los desechos líquidos, el establecimiento cuenta con dos pozos sépticos. Las aguas servidas, provenientes de lavaderos, cocina, lavavajillas y lavamanos, tienen como emisario final una servidumbre que, finalmente, cae a la quebrada Pacotúa por el costado occidental. Para la eliminación final de los desechos sólidos, cuentan con tres botaderos a campo abierto con basurero para papeles y hojas, para latas y botellas y para desechos orgánicos. 
La inspección ocular en el área locativa de la cocina y el comedor mostró condiciones técnicas e higiénico-sanitarias deficientes. La cocina contaba con área para almacenamiento de materia prima perecedera y no perecedera, pero mientras el almacenamiento de alimentos no perecederos es bueno, el de perecederos es deficiente. Los dos manipuladores de alimentos no contaban con elementos de protección indispensables como delantales, guantes y gorros, y no habían recibido capacitación.

\section{Discusión}

En el departamento de Amazonas, la vigilancia de las enfermedades transmitidas por alimentos es un evento de notificación inmediata por parte de los organismos de Salud, lo cual nos permitió detectar el brote y hacer posible su caracterización y la toma de medidas de control.

En la investigación del presente brote de intoxicación alimentaria, se comprobó por laboratorio que el alimento implicado fue la carne de caimán negro (M. niger) (8), contaminada con $B$. cereus. Esta carne iba a ser vendida como 'pescado seco' en Bogotá, por la gran demanda que tiene este alimento en la época de Semana Santa.

Dentro de los factores analizados en la visita, se encontró: un inadecuado almacenamiento de los alimentos; la carencia de un sistema de refrigeración que garantice el buen estado de los mismos; el recalentamiento impropio de los restos de comida, y el desconocimiento de las normas de procesamiento seguro de los alimentos por parte de las personas encargadas de su manipulación y preparación. Una de las formas más importantes de controlar y prevenir la aparición de estos brotes se logra mediante la difusión de su ocurrencia y su magnitud. En el presente brote, se presentó una alta proporción de personas sintomáticas, de las cuales un $36,3 \%$ requirió hospitalización, causando un impacto importante en los servicios locales de salud por el aumento súbito en la demanda de atención.

La encuesta realizada proporcionó una información clave para la identificación del alimento contaminado; es así como la tasa de ataque más alta correspondió al alimento implicado como responsable de la intoxicación, lo cual se corroboró con las pruebas de laboratorio que permitieron identificar el agente etiológico.

Una de las debilidades del estudio fue el hecho de no haber tomado muestra del material emético, a pesar de haberse recomendado. Según la guía para la toma de muestras a pacientes con sospecha de intoxicación alimentaria, se debe tomar muestra de vómito y de materia fecal a las personas que consultan con cuadros de naúseas, vómitos, arcadas, diarrea, dolor abdominal y postración, y que presentan un período de incubación de 1 a 8 horas en las cuales se sospecha que el agente etiológico puede ser Staphylococcus aureus o B. cereus $(9,10)$.

\section{Conclusiones}

Los síntomas clínicos (dolor abdominal, vómitos, diarrea, náuseas y postración), las características de la curva epidémica, el período de incubación (de 15 minutos a 11 horas) y el aislamiento de $B$. cereus en el lote de carne de caimán negro, permite concluir que este microorganismo fue el agente causal del brote de ETA en 88 personas del internado indígena Nazareth, que desayunaron el 7 de abril en el comedor de este establecimiento educativo.

Al analizar la diferencia de las tasas de ataque para cada alimento entre las personas que consumieron y las que no consumieron, la carne de caimán negro tuvo la mayor diferencia de tasas, hecho que confirman los hallazgos bacteriológicos.

Entre los factores contribuyentes encontramos el inadecuado almacenamiento, la refrigeración insuficiente después de la cocción y el recalentamiento impropio de los restos de comida.

\section{Recomendaciones}

Se debe evitar la ocurrencia de eventos similares, intensificando la vigilancia en los ocho internados indígenas ubicados en los corregimientos del departamento, así como en los comedores escolares, el ancianato, la cárcel y las bases militares.

Se deben aplicar a corto plazo las medidas que garantizan una buena conservación y manipulación de alimentos. 
Se debe dar cumplimiento a las disposiciones de las visitas sanitarias como poner en funcionamiento el pozo perforado, clorar el agua, practicar limpieza y desinfección periódica a los tanques elevados, implementar un sistema de vigilancia y control del agua, gestionar ante la Gobernación la ejecución del proyecto de adecuación del salón del comedor, elaborar un proyecto de relleno sanitario manual, coordinar con la Oficina de Atención al Ambiente programas de capacitación continuada para manipuladores de alimentos, mejorar las condiciones locativas de la cocina y revisar periódicamente los alimentos perecederos (7).

\section{Agradecimientos}

Agradecemos a las estudiantes y al personal directivo y docente del Internado Nazareth por la participación decidida durante el desarrollo del estudio de campo.

\section{Referencias}

1. OPS/OMS. Guia para el establecimiento de sistemas de VETAS y la investigación de brotes de toxo- infecciones alimentarias. Programa de Salud Pública Veterinaria. Buenos Aires: INPAZ; 1994.

2. Rebollo SE, del Castillo S. Vigilancia epidemiológica de las enfermedades transmitidas por alimentos. Boletín Epidemiológico Distrital 1997;2:1-7.

3. Ministerio del Medio Ambiente. Ley 99 de 1993, Titulo XII, Artículo 85

4. Gregg MB. Conducting a field investigation. Field Epidemiology 1996;5:44-59.

5. Ministerio de Salud. Normas técnicas de la calidad del agua potable. Decreto No. 475 del 10 de marzo de 1998.

6. Centers for Disease Control and Prevention. EpiInfo, versión 6.04b. Atlanta: CDC.

7. Secretaría de Salud del Amazonas. Acta sanitaria de visita al Internado Indígena María Auxiliadora, número 212 del 7 de junio de 1996.

8. Encarta. Caimán. Funk \& Wagnalls Corporation; 1994.

9. Benenson AS. Manual para el control de las enfermedades transmisibles. Decimosexta edición. Publicación científica 564. Washington, D.C: OPS; 1997. p.227-79.

10. Dirección Seccional de Salud de Antioquia. Protocolos de vigilancia epidemiológica. Medellín: Dirección Seccional de Salud de Antioquia 1996;25:237-55. 